$$
\begin{gathered}
\text { 부산지역 외국인 유학생의 대학급식 이용실태 및 } \\
\text { 급식 품질 속성에 대한 중요도-만족도 조사 } \\
\text { 홍 경 희 · 이 현 숙 } \\
\text { 동서대학교 식품영양학과, 교수 }
\end{gathered}
$$

\title{
An Evaluation on the Attitudes and Importance-Satisfaction on Service Quality of University Foodservice among International Students in Busan
}

\author{
Kyung Hee Hong, Hyun Sook Lee ${ }^{\dagger}$ \\ Department of Food Science and Nutrition, Dongseo University, Korea, Professor
}

\section{Corresponding author Hyun Sook Lee \\ Division of Food Science and Nutrition, Dongseo University, 47 Jurye-ro, Sassang-gu, Busan 617-716, Korea \\ Tel: (051) 320-1794 \\ Fax: (051) 320-1781 \\ E-mail: hyunlee@dongseo.ac.kr \\ Acknowledgments \\ This research was supported by grant from Dongseo University (2017).}

Received: April 2, 2019

Revised: May 7, 2019

Accepted: May 7, 2019

\begin{abstract}
Objectives: This study examined the usage status and the degree of satisfaction of university foodservice (UF) perceived by international students in Busan.

Methods: A questionnaire survey was conducted on the utilization of UF, improvement requirements, preference type and recipe, as well as the importance and satisfaction of UF quality attributes as perceived by international students $(n=604)$ at universities in the Busan area between April and June 2017.
\end{abstract}

Results: UF was 'generally satisfied' or 'very satisfied' in about $35.4 \%$ of the study population, and 'not very satisfied' or 'not satisfied at all' in approximately $11.5 \%$. Approximately $21.7 \%$ said that UF contributed to dietary life 'very much' or 'quite significantly' and $36.4 \%$ said 'not very much' or 'not at all'. The largest demand for improvement of UF was 'variety of menu' (52.0\%). The most leftover food in UF was kimchi $(30.3 \%)$ and broth/stew $(19.2 \%)$, and the major reason for having leftover was 'not to one's taste' (27.8\%). After dividing the foodservice quality attributes into 5 factors - food quality and price, sanitation, convenience, physical environment, and service environment - and analyzing the importance and satisfaction of each factor, it was shown that satisfaction was generally lower than the degree of importance. Sanitation factor was high for both importance and satisfaction of UF, while convenience factor was high for the importance but low for satisfaction of UF. Four variables in the food quality and price factor ('food taste', 'freshness of food', 'nutritive value of food', and 'reasonable price') and 3 variables in the convenience factor ('variety of menu', 'prompt food service', and 'display of the meals for the day') had high importance but low satisfaction, showing the need for an improvement on these areas.

Conclusions: Based on the study results, it is necessary to improve the food quality, as well as the price and convenience factors, and to provide various menus to increase the satisfaction of UF in international students.

Korean J Community Nutr 24(3): 208 222, 2019

KEY WORDS international student, university, foodservice, importance-satisfaction analysis

This is an Open-Access article distributed under the terms of the Creative Commons Attribution Non-Commercial License (http:// creativecommons.org/licenses/by-nc/3.0) which permits unrestricted non-commercial use, distribution, and reproduction in any medium, provided the original work is properly cited. 


\section{서 론}

최근 국내 학령인구의 급격한 감소 추세에 대비하고 대학 의 국제 경쟁력 제고를 위하여 우수한 유학생 유치를 위한 적 극적 노력이 이루어지고 있다. 교육부에서 집계한 2017년 4 월 기준 재한 외국인 유학생은 128,858 명으로, 교육부는 2023년까지 외국인 유학생 20만 명 유치를 목표로 하고 있 다[1]. 또한 외국인 학생의 양적 증가와 함께 모집지역의 다 변화로 출신국가가 다양해지는 등 유학생 저변이 확대되고 있다[1]. 우수한 역량의 다국적 유학생들을 양성하고 그들 을 한국의 지지 세력으로 확보하는 것은 고등교육의 국제화 및 국가 브랜드 가치 향상에 기여할 것으로 기대된다. 따라 서 외국인 유학생의 정주여건 및 생활환경 개선에 대한 적극 적인 관심이 요구되고 있다 $[2,3]$.

대학급식은 대학생들에게 균형 있는 영양과 양질의 급식 서비스를 제공하여 건강과 학업능률을 증진시키는데 일익을 담당하고 있으며 [4], 효율적으로 운영되는 대학급식은 급식 제공 뿐 아니라 대학 내 커뮤니티 센터의 역할을 병행할 수 있다[5]. 특히 외국인 유학생들은 대부분 교내 기숙사에서 생활하는 특성 때문에 [6] 기숙사 급식을 포함한 교내 급식 소에서의 식생활이 더욱 큰 비중을 차지하게 되어 $[7,8]$ 이 들의 영양과 건강을 고려하여 기호를 충족시키는 학교급식 의 중요성이 더욱 강조된다. 재한 유학생 대상 연구에서, 음 식에 대한 만족이 유학생활에서 중요한 요인으로 나타났고 [9], 유학생에게 기숙사 급식에 대한 만족도는 기숙사 생활 만족도를 높이는 긍정적인 역할을 하는 것으로 보고되었다 [10]. 이에 유학생들의 한국생활 적응과 유학생활 만족도 향 상을 위해 유학생들의 학교급식에 대한 욕구를 충족시킬 수 있는 양질의 급식 서비스와 차별화된 가치를 제공하는 것이 무엇보다 중요한 시점이다. 그런데 유학생들이 대학급식을 이용하는 가장 큰 이유는 의무규정 때문으로 조사되었으며 $[7,8]$, 전반적인 유학생의 대학급식에 대한 만족도는 높지 않은 것으로 나타났다 [11]. 또한 중국유학생 대상 연구에서 조사대상의 $20 \%$ 가 대학급식에 대한 품질 개선을 요구하였 으며 [9], 유학생의 기호를 반영하지 못하는 대학급식 메뉴 로 인해 식생활 스트레스를 받고 있다고 답하였다 [12]. 선 행연구에서 교내 식당을 거의 이용하지 않는다고 답한 유학 생 비율이 $68.9 \%$ 로 교내 식당 이용률이 매우 저조한 반면, 주 1-2회 이상 학교 밖에서 외식하는 비율이 $77.9 \%$, 직접 조리하여 먹는 비율은 54.9\%로 매우 높은 수준이었다 [6]. 재한 중국유학생을 대상으로 한 또 다른 연구에서도 기숙사 급식을 이용하는 비율이 배달하여 먹는 비율보다 적었고 [13],
상대적으로 직접 조리하여 먹는 빈도가 매우 높은 것으로 보 고되어 $[13,14]$, 유학생을 위한 대학급식 서비스 품질에 많 은 문제점이 존재함이 시사되었다.

유학생들이 학교급식을 이용하지 않는 주요 원인으로 기 호에 맞지 않고 다양성이 부족한 제한된 메뉴가 지적되었는 데 $[7,8]$, 대학급식소가 외부 식당과의 경쟁 환경에 대처하 지 못할 경우 급식소 운영의 어려움을 겪게 된다[15]. 따라 서 유학생의 학교급식에 대한 요구와 만족도를 다각도로 조 사하고 문제점을 파악하여 유학생을 위한 급식 서비스의 품 질을 향상시킴으로써 급식소가 경쟁력을 갖추도록 하는 것 이 당면한 과제라고 볼 수 있다. 지금까지 재한 유학생을 대 상으로 한 선행연구들은 한국에서의 식행동 및 식습관, 한국 음식에 대한 인지도 및 기호도 등 유학 후 식생활 적응에 대 한 조사가 주를 이루었고, 유학생의 대학급식 이용 실태와 만 족도에 대한 연구가 일부 이루어졌으나, 주로 중국유학생과 $[7,8,16,17]$ 일부 일본유학생을 [11] 대상으로 한 연구만 보고되고 있어 다양한 국적과 종교를 가진 유학생 전체의 대 학급식 현황에 대한 연구는 거의 없는 실정이다.

이에 따라 본 연구에서는 다양한 국적의 외국인 유학생을 대상으로 대학급식 이용 현황 및 개선 요구사항, 급식 식재 료별 선호 식품 및 조리법을 파악하고, 유학생이 인식하는 대 학급식 품질속성에 대한 중요도와 만족도를 조사 · 분석함으 로써 유학생의 급식 만족도 개선방안 마련을 위한 기초자료 를 제시하고자 하였다.

\section{연구 대상 및 방법}

\section{1. 조사 대상 및 기간}

본 연구는 전보에 기술한 바와 같이 [6] 부산 소재 대학에 재학 중인 외국인 유학생을 대상으로 2017년 4월 17일부터 6월 10 일까지 자기기입식으로 설문조사를 진행하였다. 회수 된 설문지 총 650부 중 604부 $(92.9 \%)$ 를 분석에 사용하였 다. 본 연구는 동서대학교 연구윤리위원회의 승인을 받아 진 행되었다(IRB No. 1041493-201703-HR-001-01).

\section{2. 조사 내용 및 방법}

설문지는 선행연구에서 $[7,8,17,18]$ 사용된 설문 문항 들을 기초로 하여 재구성하였고, 급식 품질속성 측정을 위한 문항은 선행연구를 $[8,11,15,18-21]$ 참고하여 본 연구 목적에 맞게 수정 - 보완 후 사용하였다. 한국어로 작성된 설 문지를 3 가지 언어 (영어, 중국어, 베트남어)로 각 이중 언어 자가 번역하였고, 번역한 설문지를 각 언어별로 소속대학에 재직하고 있는 이중 언어자 교수를 통해 감수 받았다. 본조 
사에 앞서 권역별 (중국, 동남아시아, 중앙아시아, 유럽 등) 유학생과 유학생 담당 부서 교직원들을 대상으로 예비조사 를 실시한 후 수정 · 보완한 설문지를 사용하였다.

\section{1) 일반사항}

일반사항으로는 성별, 국적, 종교, 거주기간, 거주형태, 생 활비 출처, 한 달 평균 생활비 및 식비, 자각 건강 상태 등에 대해 조사하였다.

\section{2) 대학급식 이용행태}

대상자의 대학급식 이용행태를 조사하기 위해 대학급식 이 용 현황과 잔반 실태 및 급식 개선 요구사항, 선호하는 식품 의 종류와 조리법을 조사하였다. 대학급식 이용 현황은 급식 만족도 및 식생활 기여도를 조사하였고 교내 급식을 이용하 지 않는다면 그 이유에 대해 보기를 제시하여 응답하도록 하 였다. 대상자의 대학급식 개선 요구사항을 조사하기 위해 급 식에서 많이 남기는 음식의 종류와 이유, 원하는 개선 사항 에 대해 보기를 제시하여 응답하도록 하였다. 급식 시 제공 되는 선호 음식을 조사하기 위한 문항은 식재료를 육류, 생 선류, 채소류로 분류한 후 각각 선호하는 식품의 종류와 선 호하는 조리법을 보기를 제시하여 복수응답 하도록 하였다.

\section{3) 대학급식 품질속성에 대한 중요도 및 만족도}

대학급식 품질속성을 ‘음식의 품질과 가격', ‘위생', ‘편의 성, 물리적 환경', ‘서비스 환경'의 5 개 요인으로 나누어 각 요인별 5 9개의 하부 속성으로 구성한 총 32개 문항에 대 해 중요도와 만족도를 각각 7점 리커트 척도로 조사하였다 (중요도: (1)전혀 중요하지 않다 (4) 어느 쪽도 아니다 (7) 매우 중요하다), 만족도: (1)전혀 만족하지 않는다 (4)어 느 쪽도 아니다 (7) 매우 만족한다). 또한 대학급식 개선방 안 도출을 위해 X 축은 만족도, $\mathrm{Y}$ 축은 중요도로 잡고 품질 속성들의 중요도와 만족도의 평균 점수를 기준으로 4 개의 영 역으로 나누어 중요도-만족도 분석 (Importance-Satisfaction Analysis)을 실시하였다[17].

\section{3. 자료 분석}

모든 자료 처리 및 분석은 SPSS win 20.0을 사용하였 다. 조사 항목별 분포 비율에 대한 비교는 빈도와 백분율을 구하고, 조사대상자의 성별로 $\chi^{2}$-test를 이용하여 유의성을 검증하였다. 급식 품질속성에 대한 중요도와 만족도 문항에 대하여 평균과 표준편차를 구하였으며, 성별에 따른 평균들 간 차이의 유의성 분석은 $\mathrm{t}$-test (Independent sample's t-test)로 분석하였다. 급식 품질속성 중요도와 만족도 평
가항목의 내적 일관성 검증을 위하여 크론바하 알파 (Cronbach's $\alpha$ ) 값을 이용하여 신뢰도 분석을 하였다. 모 든 통계분석의 검증을 위한 유의수준은 $\mathrm{p}<0.05$ 이었다.

\section{결 과}

\section{1. 일반사항}

조사대상자의 일반사항은 Table 1에 제시하였다 [6]. 남 학생은 $34.1 \%$, 여학생은 $65.9 \%$ 이었으며, 이 중 대부분 (97.0\%)은 기숙사에 거주하고 있었다. 국적은 총 48 개국으

Table 1. General characteristics of subjects

\begin{tabular}{|c|c|c|}
\hline Variables & Categories & $\mathrm{N}(\%)$ \\
\hline \multirow[t]{2}{*}{ Gender } & Male & $206(34.1)$ \\
\hline & Female & $398(65.9)$ \\
\hline \multirow[t]{5}{*}{ Residence type } & Dormitory & $586(97.0)$ \\
\hline & Self-boarding & $4(\quad 0.7)$ \\
\hline & Homestay & $3(0.5)$ \\
\hline & Others & $5\left(\begin{array}{ll}0.8 \\
)\end{array}\right.$ \\
\hline & No response & $6(1.0)$ \\
\hline \multirow[t]{6}{*}{ Nationality } & China & $383(63.4)$ \\
\hline & Vietnam & $80(13.2)$ \\
\hline & Uzbekistan & $50(8.3)$ \\
\hline & Indonesia & $21(3.5)$ \\
\hline & Malaysia & $8(1.3)$ \\
\hline & Others & $62(10.3)$ \\
\hline \multirow[t]{6}{*}{ Religion } & Christianity & $59(9.8)$ \\
\hline & Buddhism & $57(9.4)$ \\
\hline & Islam & $67(11.1)$ \\
\hline & None & $388(64.2)$ \\
\hline & Others & $23(3.8)$ \\
\hline & No response & $10(1.7)$ \\
\hline \multirow[t]{6}{*}{ Financial support } & Parents & 447 ( 74.0) \\
\hline & Relatives & $1(\quad 0.2)$ \\
\hline & Scholarship & $75(12.4)$ \\
\hline & Self & $34(5.6)$ \\
\hline & Others & $2(\quad 0.3)$ \\
\hline & No response & $45(7.5)$ \\
\hline \multirow{7}{*}{$\begin{array}{l}\text { Awareness } \\
\text { of health status }\end{array}$} & Very healthy & $149(24.7)$ \\
\hline & Healthy & $284(47.0)$ \\
\hline & Relatively healthy & $116(19.2)$ \\
\hline & Not very healthy & $41(6.8)$ \\
\hline & Not healthy at all & $8(1.3)$ \\
\hline & No response & $6(1.0)$ \\
\hline & Total & $604(100.0)$ \\
\hline \multicolumn{2}{|c|}{ Residence period in Korea (month) } & $8.2 \pm 6.9^{11}$ \\
\hline \multicolumn{2}{|c|}{ Monthly living cost (10,000 won) } & $62.5 \pm 39.3$ \\
\hline \multicolumn{2}{|c|}{ Monthly meal cost ( 10,000 won) } & $36.6 \pm 26.6$ \\
\hline
\end{tabular}

1) Mean $\pm S D$ 
로서, 중국이 $63.4 \%$ 으로 가장 많았고, 베트남 $13.2 \%$, 우즈 베키스탄 $8.3 \%$, 인도네시아 $3.5 \%$, 말레이시아 $1.3 \%$ 순이 었다. 대상자의 $64.2 \%$ 은 종교가 없었고, 이슬람교 $11.1 \%$, 기독교 $9.8 \%$, 불교 $9.4 \%$ 였다. 생활비는 $74.0 \%$ 가 부모님 으로부터 지원받고 있었고, 자각하는 건강 상태에 대해서는 $71.7 \%$ 가 ‘건강' 또는 ‘매우 건강'으로 답했다. 한국 거주기 간은 평균 8.2 개월, 한 달 평균 생활비는 62.5 만원, 한 달 평 균 식비는 36.6 만원이었다.

\section{2. 대학급식 이용 현황}

조사대상자의 대학급식 이용 현황은 Table 2에 제시하 였다. 대학급식에 대한 만족도는 '만족, 또는 '매우 만족’이 라고 답한 비율이 200명 (35.4\%)으로서, ‘불만족' 또는 ‘매 우 불만족’이라고 답한 비율 65명 $(11.5 \%)$ 에 비해 높았다. 대학급식이 식생활에 기여하는 정도는 '많다' 또는 '매우 많 다'가 124명 (21.7\%), ‘적다' 또는 ‘매우 적다’가 208명 $(36.4 \%)$ 으로 만족도에 비해 대학급식의 식생활 기여도는 낮은 것으로 나타났다.

대학급식을 이용하지 않는 경우, 가장 큰 이유는 식단이
다양하지 않아서' $(32.3 \%)$ 였다. 그 다음은 ‘위치 또는 이용 방법을 몰라서' $(14.4 \%)$, '맛이 없어서' $(9.6 \%)$, ‘식당 냄새 등 한국 음식 냄새가 싫어서' $(7.8 \%)$, '가격이 비싸서' (5.8\%), '메뉴에 대한 설명이 없어서' $(4.0 \%)$, 종교적 이유 를 포함하여 '먹을 수 있는 메뉴가 없어서' (3.8\%), ‘시설 또 는 위생이 마음에 들지 않아서' $(1.5 \%)$ 이었다.

대학급식의 식생활 기여도는 성별 간에 차이가 없었고, 대 학급식 만족도는 남학생보다는 여학생이 보통 이상의 만족 을 하는 비율이 다소 높게 나타났다 $(\mathrm{p}<0.05)$.

\section{3. 잔반 실태 및 개선사항}

대학급식 이용 시 주로 남기는 음식의 종류와 잔반 원인, 교내 급식 개선 요구사항을 조사한 결과는 Table 3과 같다. 대학급식에서 많이 남기는 음식은 김치 $(30.3 \%)$, 국 · 탕 · 찌개 $(19.2 \%)$, 기타 $(13.8 \%)$ 순이었고, 기타 응답으로는 양 파, 문어, 오징어 등이 있었다. 대학급식에서 음식을 남기는 이유는 ‘입맛에 맞지 않아서' $(27.8 \%)$, 양이 너무 많아서' (18.4\%), '향이나 냄새가 싫어서' $(16.3 \%)$, '먹어본 적이 없어서'(13.0\%), '싫어하는 음식이거나 식품이어서'

Table 2. The usage status of university foodservice of subjects

N (\%)

\begin{tabular}{|c|c|c|c|c|c|}
\hline & & \multirow{2}{*}{ Total } & \multicolumn{2}{|c|}{ Gender } & \multirow{2}{*}{$\chi^{2}$-value } \\
\hline & & & Male & Female & \\
\hline \multirow[t]{6}{*}{ Satisfaction } & Very satisfied & $30(5.3)$ & $8(4.2)$ & $22(5.9)$ & $10.194^{*}$ \\
\hline & Generally satisfied & $170(30.1)$ & $55(28.9)$ & $115(30.7)$ & \\
\hline & Moderate & $300(53.1)$ & $95(50.0)$ & $205(54.7)$ & \\
\hline & Not very satisfied & $51(9.0)$ & $23(12.1)$ & $28(7.5)$ & \\
\hline & Not satisfied at all & $14(2.5)$ & $9(4.7)$ & $5(\quad 1.3)$ & \\
\hline & Total & $565(100.0)$ & $190(100.0)$ & 375 (100.0) & \\
\hline \multirow[t]{6}{*}{ Contribution to diet } & Very much & $23(4.0)$ & $6(3.1)$ & $17(4.5)$ & 6.347 \\
\hline & Quite significantly & $101(17.7)$ & $32(16.7)$ & $69(18.2)$ & \\
\hline & Moderate & $240(42.0)$ & $75(39.1)$ & $165(43.4)$ & \\
\hline & Not very much & $113(19.8)$ & $49(25.5)$ & $64(16.8)$ & \\
\hline & Not at all & $95(16.6)$ & $30(15.6)$ & $65(17.1)$ & \\
\hline & Total & $572(100.0)$ & $192(100.0)$ & $380(100.0)$ & \\
\hline \multirow[t]{10}{*}{ Unvisited reason } & Lack of menu variety & $128(32.3)$ & $34(25.0)$ & $94(36.2)$ & $19.349 *$ \\
\hline & Information lack of location or way to use & $57(14.4)$ & $13(9.6)$ & $44(16.9)$ & \\
\hline & Untasty food & $38(9.6)$ & $16(11.8)$ & $15(5.8)$ & \\
\hline & Unfamiliar smell of Korean food & $31(7.8)$ & $14(10.3)$ & $24(9.2)$ & \\
\hline & Price & $23(5.8)$ & $9(6.6)$ & $14(5.4)$ & \\
\hline & No explanations of the menu & $16(4.0)$ & $6(4.4)$ & $10(3.8)$ & \\
\hline & $\begin{array}{l}\text { No menu that can eat } \\
\text { (including religious reasons) }\end{array}$ & $15(3.8)$ & $10(7.4)$ & $5(1.9)$ & \\
\hline & Facilities or the hygienic conditions & $6(1.5)$ & $3(2.2)$ & $3(1.2)$ & \\
\hline & Others & $82(20.7)$ & $31(22.8)$ & $51(19.6)$ & \\
\hline & Total & $396(100.0)$ & 136 (100.0) & $260(100.0)$ & \\
\hline
\end{tabular}

*: $\mathrm{p}<0.05$ 
212 ·외국인 유학생의 대학급식 이용실태 및 만족도 조사

Table 3. Leftover foods and their reasons and demand for improvement in university foodservice of subjects

N (\%)

\begin{tabular}{|c|c|c|c|c|}
\hline & \multirow{2}{*}{ Total } & \multicolumn{2}{|c|}{ Gender } & \multirow{2}{*}{$\chi^{2}$-value } \\
\hline & & Male & Female & \\
\hline \multicolumn{5}{|l|}{ Leftover foods } \\
\hline Kimchi & $139(30.3)$ & $54(36.7)$ & $85(27.3)$ & 8.397 \\
\hline Broth/stew & $88(19.2)$ & $24(16.3)$ & $64(20.6)$ & \\
\hline Rice & $54(11.8)$ & $11(7.5)$ & $43(13.8)$ & \\
\hline Dessert & $37(8.1)$ & $12(8.2)$ & $25(8.0)$ & \\
\hline Fish & $37(8.1)$ & $12(8.2)$ & $25(8.0)$ & \\
\hline Meat & $23(5.0)$ & $9(6.1)$ & $14(4.5)$ & \\
\hline Vegetables & $17(3.7)$ & $4(2.7)$ & $13(4.2)$ & \\
\hline Others & $63(13.8)$ & $21(14.3)$ & $42(13.5)$ & \\
\hline Total & $458(100.0)$ & $147(100.0)$ & $311(100.0)$ & \\
\hline \multicolumn{5}{|l|}{ Reasons for leftover } \\
\hline Not to one's taste & $128(27.8)$ & $43(29.5)$ & $85(27.0)$ & $17.309 * *$ \\
\hline Too much amount & $85(18.4)$ & $13(8.9)$ & $72(22.9)$ & \\
\hline Dislike flavor & $75(16.3)$ & $28(19.2)$ & $47(14.9)$ & \\
\hline Have not eaten before & $60(13.0)$ & $24(16.4)$ & $36(11.4)$ & \\
\hline Dislike dish or food & $55(11.9)$ & $23(15.8)$ & $32(10.2)$ & \\
\hline Others & $58(12.6)$ & $15(10.3)$ & $43(13.7)$ & \\
\hline Total & $461(100.0)$ & $146(100.0)$ & $315(100.0)$ & \\
\hline \multicolumn{5}{|l|}{ Demand for improvement } \\
\hline Variety of menu & $178(52.0)$ & $53(45.7)$ & $125(55.3)$ & 9.216 \\
\hline Taste & $51(14.9)$ & $14(12.1)$ & $37(16.4)$ & \\
\hline Decrease in price & $38(11.1)$ & $17(14.7)$ & $21(9.3)$ & \\
\hline Increase in portion size & $34(9.9)$ & $17(14.7)$ & $17(7.5)$ & \\
\hline Kindness of staff & $9(2.6)$ & $3(2.6)$ & $6(2.7)$ & \\
\hline Sanitation and cleanliness & $5(1.5)$ & $1(\quad 0.9)$ & $4(1.8)$ & \\
\hline Ambience of cafeteria & $0(\quad 0.0)$ & $0(\quad 0.0)$ & $0(\quad 0.0)$ & \\
\hline Others & $27(7.9)$ & $11(9.5)$ & $16(7.1)$ & \\
\hline Total & $342(100.0)$ & $116(100.0)$ & $226(100.0)$ & \\
\hline
\end{tabular}

\section{$(11.9 \%)$ 순이었다.}

조사대상자의 대학급식 개선 요구 사항으로는 ‘메뉴의 다 양화'가 $52.0 \%$ 로 가장 많았고, ‘음식의 맛 개선' $14.9 \%$, ‘급식비 인하' $11.1 \%$, ‘ 1 인 분량 증가' $9.9 \%$, ‘급식종사자 의 친절' $2.6 \%$, ‘급식소 위생 및 청결' $1.5 \%$ 순이었다. 기타 요구 사항으로는 매운 음식 줄이기, 할랄음식 제공 등이 있 었다. 대학급식에서 많이 남기는 음식의 종류는 성별에 따른 차이는 없었다. 그러나 대학급식에서 음식을 남기는 이유는 성별에 따른 차이가 있어서, 남학생은 '입맛에 맞지 않아서, (29.5\%), ‘향이나 냄새가 싫어서' $(19.2 \%)$, ‘먹어본 적이 없어서' $(16.4 \%)$, ‘싫어하는 음식이거나 식품이어서' (15.8\%) 순이었고, 여학생은 ‘입맛에 맞지 않아서' $(27.0 \%)$, 양이 너 무 많아서' (22.9\%), '향이나 냄새가 싫어서' (14.9\%), '먹 어본 적이 없어서' $(11.4 \%)$ 순으로서, 여학생은 배식양이 많
은 것이 잔반의 주된 이유 중의 하나인 것으로 나타났다 $(\mathrm{p}<0.01)$. 교내 급식에 원하는 개선 사항에서는 성별에 따 른 통계적 유의성이 없었다.

\section{4. 급식 선호 식품 및 조리법}

한국에서 주로 사용하는 식재료를 중심으로 육류, 생선류, 채소류로 나누어 식품군별 조사대상자의 급식에서의 선호 식 품과 조리법을 조사한 결과를 각각 Table 4와 Table 5에 나타내었다. 육류 중에서는 소고기 (64.2\%), 닭고기 (40.7\%), 돼지고기 (29.0\%), 양고기 (12.9\%), 오리고기 (9.3\%) 순으 로 좋아하는 것으로 나타났다. 생선류 중에서는 오징어 (42.6\%)를 가장 선호하였고, 그 다음 낙지 (22.0\%), 꽁치 $(21.8 \%)$, 장어 $(18.8 \%)$, 갈치 $(16.2 \%)$, 고등어와 임연수 어 (각각 $16.0 \%)$, 조기 $(14.9 \%)$, 삼치 $(14.1 \%)$, 가자미 
Table 4. Preference of materials in food group of subjects

\begin{tabular}{|c|c|c|c|c|c|}
\hline \multirow{2}{*}{ Food group } & \multirow{2}{*}{ Food materials } & \multirow{2}{*}{ Total } & \multicolumn{2}{|c|}{ Gender } & \multirow{2}{*}{$\chi^{2}$-value } \\
\hline & & & Male & Female & \\
\hline \multirow[t]{6}{*}{ Meats } & Beef & $354(64.2)$ & $125(69.4)$ & $229(61.7)$ & $20.871 * *$ \\
\hline & Chicken & $224(40.7)$ & $62(34.4)$ & $162(43.7)$ & \\
\hline & Pork & $160(29.0)$ & $45(25.0)$ & $115(31.0)$ & \\
\hline & Lamb & $71(12.9)$ & $35(19.4)$ & $36(9.7)$ & \\
\hline & Duck & $51(9.3)$ & $20(11.1)$ & $31(8.4)$ & \\
\hline & Total & $551(100.0)$ & $180(100.0)$ & $371(100.0)$ & \\
\hline \multirow[t]{11}{*}{ Fishes } & Squid & $215(42.6)$ & $56(36.6)$ & $159(45.2)$ & $24.976 * *$ \\
\hline & Small octopus & 111 ( 22.0) & $28(18.3)$ & $83(23.6)$ & \\
\hline & Mackerel pike & $110(21.8)$ & $26(17.0)$ & $84(23.9)$ & \\
\hline & Eel & $95(18.8)$ & $18(11.8)$ & $77(21.9)$ & \\
\hline & Cutlass fish & $82(16.2)$ & 32 ( 20.9) & $50(14.2)$ & \\
\hline & Atka Mackerel & $81(16.0)$ & $22(14.4)$ & $59(16.8)$ & \\
\hline & Mackerel & $81(16.0)$ & $20(13.1)$ & 61 ( 17.3) & \\
\hline & Croaker & $75(14.9)$ & $24(15.7)$ & $51(14.5)$ & \\
\hline & Spanish mackerel & $71(14.1)$ & $27(17.6)$ & $44(12.5)$ & \\
\hline & Flatfish & $63(12.5)$ & $24(15.7)$ & $39(11.1)$ & \\
\hline & Total & 505 (100.0) & 153 (100.0) & $352(100.0)$ & \\
\hline \multirow[t]{11}{*}{ Vegetables } & Chinese cabbage & $224(40.9)$ & $72(41.4)$ & $152(40.6)$ & $31.775 * * *$ \\
\hline & Cucumber & $222(40.5)$ & $77(44.3)$ & $145(38.8)$ & \\
\hline & Broccoli & $216(39.4)$ & $54(31.0)$ & $162(43.3)$ & \\
\hline & Spinach & $158(28.8)$ & $39(22.4)$ & $119(31.8)$ & \\
\hline & Eggplant & $133(24.3)$ & $42(24.1)$ & 91 ( 24.3) & \\
\hline & Lotus root & $120(21.9)$ & $27(15.5)$ & $93(24.9)$ & \\
\hline & Zucchini & $97(17.7)$ & $18(10.3)$ & $79(21.1)$ & \\
\hline & Sesame leaf & $31(5.7)$ & $13(7.5)$ & $18(4.8)$ & \\
\hline & Platycodon & $13(2.4)$ & $5(2.9)$ & $8(2.1)$ & \\
\hline & Burdock & $12(\quad 2.2)$ & $3(\quad 1.7)$ & $9(2.4)$ & \\
\hline & Total & 548 (100.0) & 174 (100.0) & 374 (100.0) & \\
\hline
\end{tabular}

**: $p<0.01, * * *: p<0.001$

(12.5\%) 등으로 비슷한 선호도를 보였다. 채소류 중에서는 배추 $(40.9 \%)$, 오이 (40.5\%), 브로콜리 (39.4\%)를 좋아하 는 것으로 나타났고, 그 다음으로 시금치 $(28.8 \%)$, 가지 (24.3\%), 연근 $(21.9 \%)$, 호박 $(17.7 \%)$ 순이었다. 깻잎 (5.7\%), 도라지 (2.4\%), 우엉 (2.2\%)은 다른 채소류에 비 해 선호도가 낮았다. 성별로 비교하였을 때, 남학생이 여학 생에 비해 양고기와 오리고기를 좋아하는 비율이 높았고 여 학생은 남학생보다 닭고기와 돼지고기를 좋아하는 비율이 높 았다 $(\mathrm{p}<0.01)$. 또한 생선류 중 갈치, 조기, 삼치, 가자미를 제외하고는 여학생이 남학생에 비해 전반적으로 생선을 더 선호하는 것으로 나타났다 $(\mathrm{p}<0.01)$. 채소류 중에서는 남학 생은 오이 (44.3\%)를, 여학생은 브로콜리 (43.3\%)를 가장 선호하였다 $(\mathrm{p}<0.001)$.

육류 조리법 중에서는 구이 (51.5\%)를 가장 선호하였고,
그 다음이 볶음 $(42.8 \%)$ 이었다. 육류의 튀김 $(21.4 \%)$, 찜 (20.0\%), 조림 (17.8\%)은 비슷한 선호도를 보였으며 끓이 기 (11.3\%)가 가장 낮은 선호도를 보였다. 유학생들은 육류 조리 시 찜, 조림, 끓이기 등의 습열조리보다 구이, 볶음 등 건열조리를 더 좋아하는 것으로 나타났다. 생선류도 구이 (35.3\%)를 가장 선호하였으며, 그 다음 튀김 (27.3\%), 끓 이기 (24.3\%), 볶음 $(23.7 \%)$ 순이었다. 생선 조리법 중 찜 (13.7\%)과 조림 (10.9\%)은 선호도가 낮은 편으로 나타나, 생선 조리 역시 찜, 조림 등의 습열조리보다 구이를 선호하 는 것을 알 수 있었다. 채소류 조리법으로는 생채 - 샐러드가 $43.9 \%$ 로 가장 선호도가 높았고, 다음이 끓이기 (34.0\%), 숙 채와 나물 (31.8\%), 튀김 (14.1\%) 순이었으며, 조림과 절임 (4.8\%)이 가장 선호도가 낮았다 (Table 5). 성별 선호하는 조리법은, 남학생은 구이 $(47.5 \%)$, 볶음 $(38.0 \%)$, 튀김 
214 - 외국인 유학생의 대학급식 이용실태 및 만족도 조사

Table 5. Preference of cooking method in food group of subjects

$N(\%)$

\begin{tabular}{|c|c|c|c|c|c|}
\hline \multirow{2}{*}{ Food group } & \multirow{2}{*}{ Cooking methods } & \multirow{2}{*}{ Total } & \multicolumn{2}{|c|}{ Gender } & \multirow{2}{*}{$\chi^{2}$-value } \\
\hline & & & Male & Female & \\
\hline \multirow[t]{7}{*}{ Meats } & Roasting & $284(51.5)$ & $85(47.5)$ & $199(53.5)$ & $26.698 * * *$ \\
\hline & Stir-frying & $236(42.8)$ & $68(38.0)$ & $168(45.2)$ & \\
\hline & Deep-fat frying & $118(21.4)$ & $57(31.8)$ & $61(16.4)$ & \\
\hline & Steaming & $110(20.0)$ & $26(14.5)$ & $84(22.6)$ & \\
\hline & Braising & $98(17.8)$ & $34(19.0)$ & $64(17.2)$ & \\
\hline & Boiling & $62(11.3)$ & $19(10.6)$ & $43(11.6)$ & \\
\hline & Total & $551(100.0)$ & 179 (100.0) & $372(100.0)$ & \\
\hline \multirow[t]{7}{*}{ Fishes } & Roasting & $190(35.3)$ & $56(32.9)$ & $134(36.3)$ & $23.869 * *$ \\
\hline & Deep-fat frying & $147(27.3)$ & $66(38.8)$ & $81(22.0)$ & \\
\hline & Boiling & $131(24.3)$ & $30(17.6)$ & $101(27.4)$ & \\
\hline & Stir-frying & $128(23.7)$ & $37(21.8)$ & $91(24.7)$ & \\
\hline & Steaming & $74(13.7)$ & $24(14.1)$ & $50(13.6)$ & \\
\hline & Braising & $59(10.9)$ & $18(10.6)$ & $41(11.1)$ & \\
\hline & Total & $539(100.0)$ & $170(100.0)$ & $369(100.0)$ & \\
\hline \multirow[t]{6}{*}{ Vegetables } & Saengchae/Salad & $240(43.9)$ & $79(45.1)$ & $161(43.3)$ & 7.355 \\
\hline & Boiling & $186(34.0)$ & $55(31.4)$ & $131(35.2)$ & \\
\hline & Sukchae (blanching and seasoning) & $174(31.8)$ & $45(25.7)$ & $129(34.7)$ & \\
\hline & Deep-fat frying & $77(14.1)$ & $30(17.1)$ & $47(12.6)$ & \\
\hline & Braising/Salting & $26(4.8)$ & $8(4.6)$ & $18(4.8)$ & \\
\hline & Total & 547 (100.0) & 175 (100.0) & $372(100.0)$ & \\
\hline
\end{tabular}

$* *: p<0.01, * * *: p<0.001$

(31.8\%), 조림 (19.0\%), 찜 (14.5\%)의 순이었고, 여학생은 구이 (53.5\%), 볶음 $(45.2 \%)$, 찜 (22.6\%), 조림 (17.2\%), 튀김 $(16.4 \%)$ 의 순으로서 남학생이 여학생에 비해 튀김에 대한 선호도가 높고, 여학생은 남학생보다 찜에 대한 선호도 가 높은 것으로 나타났다 ( $\mathrm{p}<0.001)$. 생선류 조리법 역시 남 학생은 튀김 (38.8\%)을 가장 선호하는 반면, 여학생은 구이 $(36.3 \%)$ 와 끓이기 $(27.4 \%)$ 를 선호하여 성별 차이를 보였 다 $(\mathrm{p}<0.01)$.

\section{5. 급식 품질속성에 대한 중요도 및 만족도}

대학급식 품질속성 평가 항목 전체에 대한 신뢰도 분석 결 과, 크론바하 알파 값이 0.978 이었고, 각 요인별 크론바하 알파 값은 음식의 품질과 가격, 위생, 편의성, 물리적 환경, 서비스 환경이 각각 $0.914,0.960,0.881,0.895,0.924$ 로 문항 간 내적 일관성이 신뢰할 만한 수준이었다.

조사대상자의 급식 품질속성에 대한 중요도와 만족도를 분 석한 결과는 Fig. 1 과 같다. 총 32 개 항목의 평균점수 (7점 척도)는 중요도 6.00 점, 만족도 5.21점으로서, 전반적으로 중요도에 비해 만족도가 낮은 것으로 나타났다.

조사대상자가 급식 품질속성 5가지 요인 중 가장 중요하 게 생각하는 것은 ‘위생' 요인(6.42점)이었고, 그 다음으로
‘서비스 환경' 요인 (6.09점), ‘편의성' 요인 (6.03점), ‘음식 의 품질과 가격' 요인 (5.95점), ‘물리적 환경' 요인 (5.52 점) 순이었다. 만족도 점수 역시 ‘위생' 요인 (5.56점)과 ‘서 비스 환경' 요인 (5.50점)이 높았고, 그 다음으로 ‘물리적 환 경' 요인 (5.18점), ‘음식의 품질과 가격' 요인 (4.94점), ‘편 의성, 요인 (4.88점) 순으로 나타났다. 중요도 점수와 만족 도 점수를 기준으로 하여 I(집중개선, concentrate here), II(유지, keep up the good work), III (낮은 중요도, low priority), IV(과잉, possible overkill) 등 4 개 분면으로 나누어 중요도-만족도 분석을 실시한 결과, 중요도는 높게 평가하였으나 만족도는 평균값 이하로 낮게 평가하여 대학 급식에서 우선적으로 심층 관리가 필요하다고 평가된 부분 (I)은 ‘편의성' 요인으로 나타났다. 중요도와 만족도 점수가 함께 높아 앞으로 현재수준을 잘 유지해야 할 부분 (II)은 ‘위 생'과 '서비스 환경' 요인으로 나타났다. 한편 ‘물리적 환경' 은 중요도와 만족도가 모두 낮아 유학생의 급식에서 가장 중 요하지 않은 요인 (III)으로 나타났다.

각 요인별 속성에 대해 중요도와 만족도를 분석한 결과 ‘음 식의 품질과 가격, 요인의 8개 속성 중 중요도 점수는 ‘음식 의 신선도'(6.33점), ‘음식의 맛'(6.29점), ‘음식의 영양가' (6.16점), ‘적정 가격'(6.14점), ‘음식의 간’ (5.96점), ‘음 


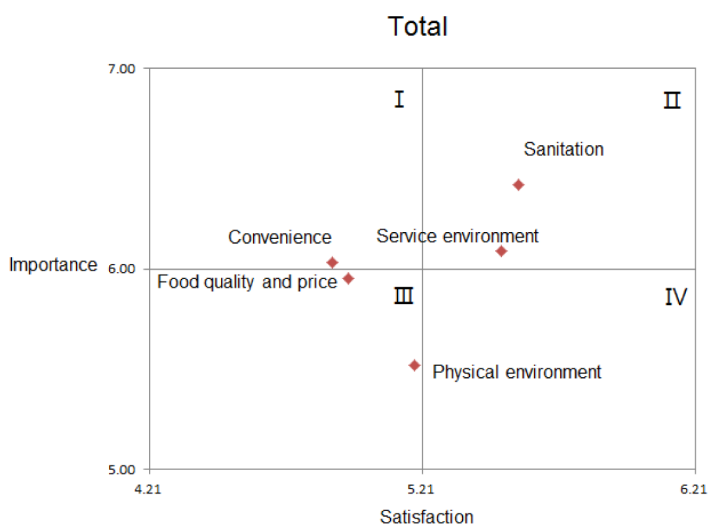

Sanitation

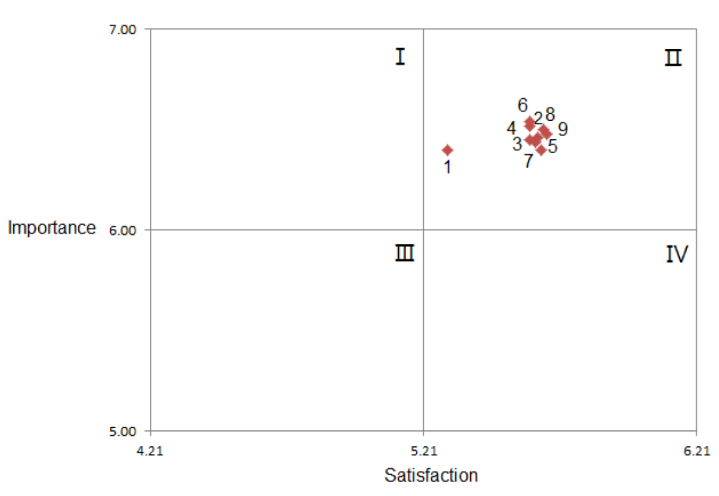

Physical environment

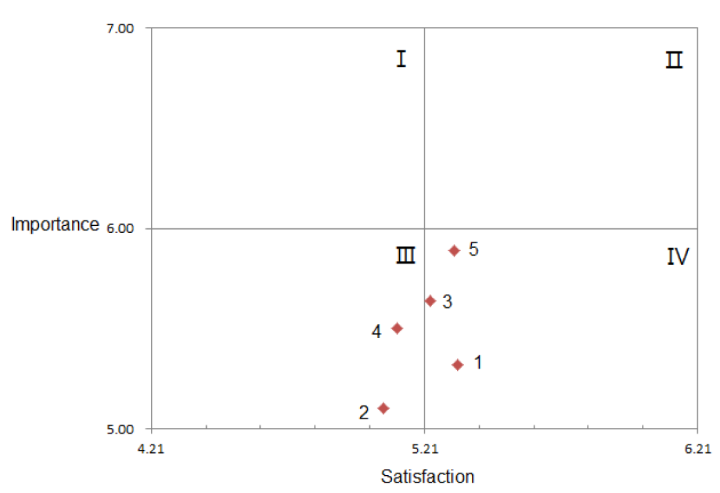

Food quality and price

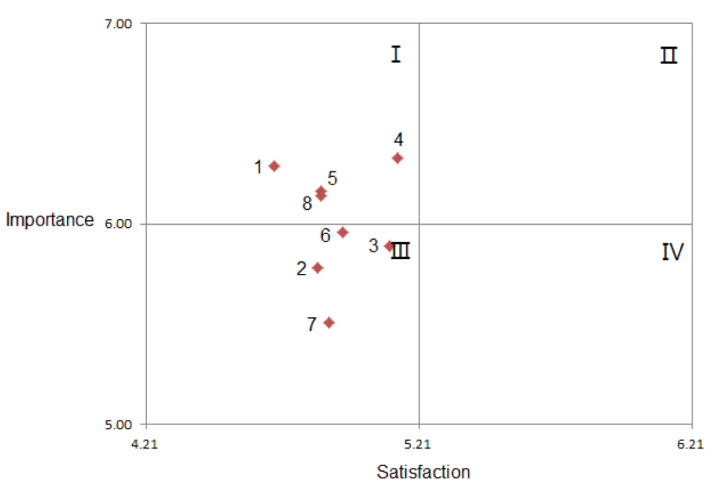

Convenience

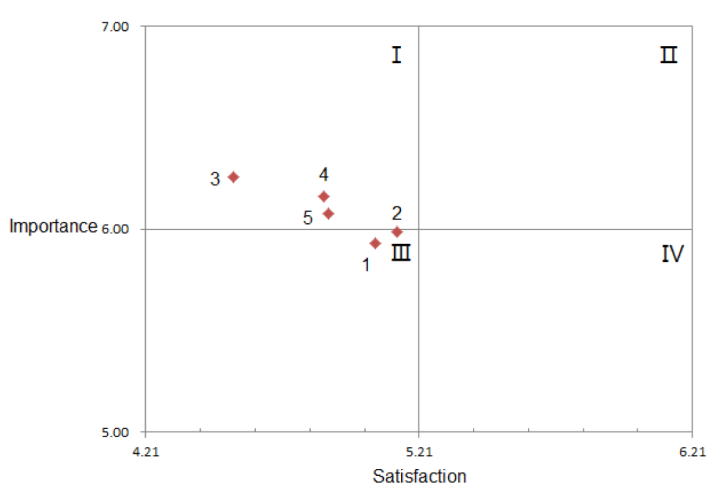

Service environment

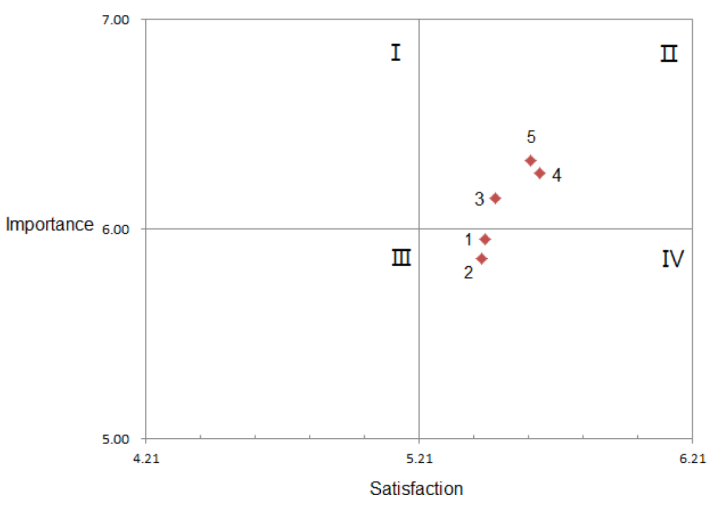

Fig. 1. Importance-satisfaction analysis chart for the university foodservice selection attributes

Quadrant I: High importance/Low satisfaction labeled as "Concentrate here".

Quadrant II: High importance/Low satisfaction labeled as "Keep up the good work".

Quadrant III: Low importance/Low satisfaction labeled as "Low priority."

Quadrant IV: Low importance/Low satisfaction labeled as "Possible overkill."

Food quality and price - 1. Food taste, 2. Adequate portion size, 3. Proper food temperature, 4. Freshness of food, 5. Nutritive value of food, 6. Saltiness of food, 7. Harmony of main and side dishes, 8 . Reasonable price

Sanitation - 1. Cleanliness of food, 2. Cleanliness of dining room, 3. Ventilation of dining room, 4. Cleanliness of toilet, 5. Sanitation of employee, 6. Sanitation of dishes and cutlery, 7. Cleanliness of cook's uniform, 8. Sanitation of cooking and food distribution, 9. Cleanliness of floors of kitchen and dining room

Convenience - 1. Waiting time for meal, 2. Short walking distance, 3. Variety or menu, 4. Prompt food service, 5. Display of the meals for the day

Physical environment - 1. Interior of dining area, 2. Background music 3. Food appearance, 4. Foodservice event, 5. Location of cafeteria

Service environment - 1. Comfortable seats, 2. Functionality as resting place, 3. Pleasant dining environment, 4. Presence of drinking water facilities, serviettes and mirrors, 5 . Kindness of employee 
식의 온도' (5.89점), ‘적정 1 인 분량' (5.78점), ‘주식과 부 식의 조화' (5.51점) 순으로 높았고, 만족도 점수는 ‘음식의 신선도' (5.13점), ‘음식의 온도' (5.10점), ‘음식의 간' 4.93 점), ‘주식과 부식의 조화'(4.88점), '적정 가격', ‘음식의 영 양가' (각각 4.85점), '적정 1 인 분량' (4.84점), ‘음식의 맛' (4.68점) 순이었다. 이 8개 속성 중 중요도는 높은데 비해 만족도가 낮아 앞으로 집중해서 개선해야 할 속성 (I)은 ‘음 식의 맛', ‘음식의 신선도', ‘음식의 영양가', ‘적정 가격'으로 나타났다. 급식의 ‘위생' 요인의 9개 속성 (‘음식의 위생', '식 당의 청결' '식당의 환기', '화장실의 청결' '종사원의 위생', '식기의 위생', '조리원의 복장 청결', '위생적인 조리 · 배 식', ‘주방 및 식당 홀 바닥의 청결')은 모두 중요도가 6.5점 내외로 매우 높았고, 만족도 점수도 모두 5.3점 이상으로 평 균점수 이상으로 비교적 높았으며, 속성 간 중요도와 만족도 점수에 큰 차이 없이 모두 높게 나타나, 모든 속성이 현재 수 준을 그대로 유지해야 할 속성 (II)으로 나타났다. 급식의 '편 의성' 요인 속성의 중요도 점수는 ‘다양한 메뉴'(6.26점), '원활한 배식'(6.16점), '식단 내용 게시'(6.08점), '식당까 지의 이동거리'(5.99점), '식사 대기시간' (5.93점) 순이었 고, 만족도 점수는 '식당까지의 이동거리'(5.13점), '식사 대 기시간'(5.05점), '식단 내용 게시'(4.88점), ‘원활한 배식' (4.86점), ‘다양한 메뉴'(4.53점) 순으로 높았다. 이 5 개 속 성 중 ‘다양한 메뉴', ‘원활한 배식', ‘식단 내용 게시'는 중요 도는 높으나 만족도가 높지 않아(I) 앞으로 이 부분에 대한
우선적 개선이 필요할 것으로 보인다. ‘물리적 환경' 요인 속 성은 중요도 점수가 비교적 낮아 5 개 속성 모두 평균점수 6.0 점보다 낮았고, '식당의 위치' (5.89점), ‘음식의 외관' (5.64 점), '급식 이벤트'(5.50점), '식당 인테리어'(5.32점), ‘배 경음악' (5.10점) 순이었다. 만족도는 ‘식당 인테리어' (5.33 점), '식당의 위치'(5.32점), ‘음식의 외관'(5.23점), '급식 이벤트'(5.11점), ‘배경음악'(5.06점) 순으로 평가점수가 높았다. 이 중 ‘배경음악'과 ‘급식 이벤트'는 중요도와 만족 도가 모두 낮아(III) 급식품질에 그리 크게 고려하지 않아도 되는 속성인 것으로 나타났다. '서비스 환경' 요인에서는 ‘종 사원의 친절'(6.33점), ‘식사 후 냅킨 - 거울 - 급수시설의 구비'(6.27점), ‘쾌적한 식사 환경'(6.15점), '편안한 좌석' (5.95점), ‘휴식 장소의 기능' (5.86점) 순으로 중요도 점수 가 높았고, 만족도 점수는 '식사 후 냅킨 - 거울 - 급수시설의 구비'(5.65점), ‘종사원의 친절' (5.62점), 쾌적한 식사 환 경'(5.49점), ‘편안한 좌석'(5.45점), ‘휴식 장소의 기능' (5.44점) 순이었다. 이 5 개 속성 중 '쾌적한 식사 환경'과 '식사 후 냅킨 · 거울 - 급수시설의 구비', ‘종사원의 친절'은 중요도와 만족도 점수가 모두 높아 현재 수준을 잘 유지해야 할 속성 (II)으로 나타났다.

조사대상자의 성별로 급식 품질속성에 대한 중요도 및 만 족도 점수를 분석한 결과를 Table 6에 나타내었다. 전체 급 식 품질 속성에 대한 중요도 점수는 여학생 $(6.13 \pm 1.16)$ 이 남학생 $(5.87 \pm 1.39)$ 보다 유의하게 높았고 $(\mathrm{p}<0.01)$, 만족

Table 6. The importance and satisfaction levels of the university foodservice by gender

\begin{tabular}{|c|c|c|c|c|c|c|}
\hline \multicolumn{2}{|c|}{ Factor and variables } & \multirow{2}{*}{$\begin{array}{l}\text { Gender } \\
\text { Male }\end{array}$} & \multirow{2}{*}{$\frac{\text { Importance }}{6.04 \pm 1.39^{11}}$} & \multirow{2}{*}{$\frac{\text { t-value }}{-3.559 * * *}$} & \multirow{2}{*}{$\frac{\text { Satisfaction }}{4.77 \pm 1.55^{2)}}$} & \multirow{2}{*}{$\frac{\text { t-value }}{0.735}$} \\
\hline Food quality and price & Food taste & & & & & \\
\hline & & Female & $6.45 \pm 1.11$ & & $4.66 \pm 1.52$ & \\
\hline & Adequate portion size & Male & $5.68 \pm 1.39$ & -1.205 & $4.73 \pm 1.54$ & -1.169 \\
\hline & & Female & $5.84 \pm 1.42$ & & $4.91 \pm 1.55$ & \\
\hline & Proper food temperature & Male & $5.68 \pm 1.46$ & $-2.506 *$ & $5.32 \pm 3.33$ & 1.406 \\
\hline & & Female & $6.01 \pm 1.36$ & & $5.01 \pm 1.54$ & \\
\hline & Freshness of food & Male & $6.05 \pm 1.42$ & $-3.835 * * *$ & $5.16 \pm 1.43$ & 0.187 \\
\hline & & Female & $6.49 \pm 1.08$ & & $5.13 \pm 1.45$ & \\
\hline & Nutritive value of food & Male & $5.94 \pm 1.43$ & $-2.813^{* *}$ & $5.06 \pm 1.40$ & $2.039 *$ \\
\hline & & Female & $6.28 \pm 1.22$ & & $4.76 \pm 1.59$ & \\
\hline & Saltiness of food & Male & $5.60 \pm 1.56$ & $4.150 * * *$ & $5.05 \pm 1.39$ & 1.199 \\
\hline & & Female & $6.15 \pm 1.31$ & & $4.89 \pm 1.51$ & \\
\hline & Harmony of main and side dishes & Male & $5.25 \pm 1.71$ & $-2.428 *$ & $4.93 \pm 1.54$ & 0.420 \\
\hline & & Female & $5.64 \pm 1.65$ & & $4.87 \pm 1.51$ & \\
\hline & Reasonable price & Male & $5.87 \pm 1.46$ & $-3.457 * *$ & $4.91 \pm 1.53$ & 0.528 \\
\hline & & Female & $6.29 \pm 1.19$ & & $4.84 \pm 1.54$ & \\
\hline & Total & Male & $5.76 \pm 1.45$ & $-2.683^{*}$ & $4.99 \pm 1.71$ & 1.246 \\
\hline & & Female & $6.14 \pm 1.29$ & & $4.88 \pm 1.53$ & \\
\hline & & Total & $5.95 \pm 1.37$ & & $4.94 \pm 1.62$ & \\
\hline
\end{tabular}


Table 6. continued

\begin{tabular}{|c|c|c|c|c|c|c|}
\hline \multicolumn{2}{|c|}{ Factor and variables } & Gender & Importance & t-value & Satisfaction & t-value \\
\hline \multirow[t]{21}{*}{ Sanitation } & \multirow[t]{2}{*}{ Cleanliness of food } & Male & $6.21 \pm 1.36$ & $-3.544 * * *$ & $5.37 \pm 1.41$ & 0.667 \\
\hline & & Female & $6.59 \pm 1.03$ & & $5.28 \pm 1.45$ & \\
\hline & \multirow[t]{2}{*}{ Cleanliness of dining room } & Male & $6.35 \pm 1.19$ & $-2.649 * *$ & $5.48 \pm 1.46$ & -1.358 \\
\hline & & Female & $6.63 \pm 0.86$ & & $5.67 \pm 1.25$ & \\
\hline & \multirow[t]{2}{*}{ Ventilation of dining room } & Male & $6.23 \pm 1.18$ & $-3.302 * * *$ & $5.43 \pm 1.38$ & $-1.998 *$ \\
\hline & & Female & $6.57 \pm 0.85$ & & $5.68 \pm 1.26$ & \\
\hline & \multirow[t]{2}{*}{ Cleanliness of toilet } & Male & $6.27 \pm 1.23$ & $-2.750 * *$ & $5.55 \pm 1.39$ & -0.982 \\
\hline & & Female & $6.57 \pm 0.92$ & & $5.68 \pm 1.29$ & \\
\hline & \multirow[t]{2}{*}{ Sanitation of employee } & Male & $6.19 \pm 1.25$ & $-3.587 * *$ & $5.44 \pm 1.43$ & $-2.163^{*}$ \\
\hline & & Female & $6.58 \pm 0.87$ & & $5.72 \pm 1.26$ & \\
\hline & \multirow[t]{2}{*}{ Sanitation of dishes and cutlery } & Male & $6.33 \pm 1.18$ & $-3.276 * * *$ & $5.48 \pm 1.39$ & -1.347 \\
\hline & & Female & $6.67 \pm 0.81$ & & $5.66 \pm 1.28$ & \\
\hline & \multirow[t]{2}{*}{ Cleanliness of cook's uniform } & Male & $6.18 \pm 1.22$ & $-3.184 * * *$ & $5.48 \pm 1.40$ & -1.873 \\
\hline & & Female & $6.53 \pm 0.92$ & & $5.72 \pm 1.25$ & \\
\hline & \multirow{2}{*}{$\begin{array}{l}\text { Sanitation of cooking and food } \\
\text { distribution }\end{array}$} & Male & $6.25 \pm 1.25$ & $-3.583 * * *$ & $5.55 \pm 1.36$ & -1.171 \\
\hline & & Female & $6.64 \pm 0.82$ & & $5.70 \pm 1.26$ & \\
\hline & \multirow{2}{*}{$\begin{array}{l}\text { Cleanliness of floors of kitchen and } \\
\text { dining room }\end{array}$} & Male & $6.25 \pm 1.27$ & $-3.193 * * *$ & $5.55 \pm 1.36$ & -1.377 \\
\hline & & Female & $6.60 \pm 0.88$ & & $5.72 \pm 1.24$ & \\
\hline & \multirow[t]{3}{*}{ Total } & Male & $6.25 \pm 1.24$ & $-14.380 * * *$ & $5.48 \pm 1.40$ & $-3.268 * *$ \\
\hline & & Female & $6.60 \pm 0.89$ & & $5.65 \pm 1.28$ & \\
\hline & & Total & $6.42 \pm 1.07$ & & $5.56 \pm 1.34$ & \\
\hline \multirow[t]{13}{*}{ Convenience } & \multirow[t]{2}{*}{ Waiting time for meal } & Male & $5.70 \pm 1.56$ & $-2.713^{* *}$ & $4.82 \pm 1.54$ & $-2.354 *$ \\
\hline & & Female & $6.06 \pm 1.25$ & & $5.15 \pm 1.45$ & \\
\hline & \multirow[t]{2}{*}{ Short walking distance } & Male & $5.71 \pm 1.44$ & $-3.384 * *$ & $4.98 \pm 1.60$ & -1.523 \\
\hline & & Female & $6.13 \pm 1.23$ & & $5.21 \pm 1.57$ & \\
\hline & \multirow[t]{2}{*}{ Variety or menu } & Male & $5.93 \pm 1.46$ & $-4.553 * * *$ & $4.65 \pm 1.53$ & 1.081 \\
\hline & & Female & $6.44 \pm 1.02$ & & $4.48 \pm 1.70$ & \\
\hline & \multirow[t]{2}{*}{ Prompt food service } & Male & $5.78 \pm 1.42$ & $-5.105 * * *$ & $4.93 \pm 1.40$ & 0.723 \\
\hline & & Female & $6.36 \pm 1.06$ & & $4.83 \pm 1.55$ & \\
\hline & \multirow[t]{2}{*}{ Display of the meals for the day } & Male & $5.83 \pm 1.42$ & $-3.292 * *$ & $4.90 \pm 1.61$ & 0.085 \\
\hline & & Female & $6.22 \pm 1.17$ & & $4.88 \pm 1.60$ & \\
\hline & \multirow[t]{3}{*}{ Total } & Male & $5.79 \pm 1.46$ & $-6.116 * * *$ & $4.86 \pm 1.54$ & -0.379 \\
\hline & & Female & $6.26 \pm 0.95$ & & $4.91 \pm 1.57$ & \\
\hline & & Total & $6.03 \pm 1.20$ & & $4.88 \pm 1.56$ & \\
\hline \multirow[t]{13}{*}{ Physical environment } & \multirow[t]{2}{*}{ Interior of dining area } & Male & $5.36 \pm 1.51$ & 0.327 & $5.21 \pm 1.34$ & -1.492 \\
\hline & & Female & $5.31 \pm 1.60$ & & $5.40 \pm 1.40$ & \\
\hline & \multirow[t]{2}{*}{ Background music } & Male & $5.21 \pm 1.63$ & 0.952 & $4.86 \pm 1.63$ & -1.947 \\
\hline & & Female & $5.05 \pm 1.73$ & & $5.16 \pm 1.59$ & \\
\hline & Food appearance & Male & $5.68 \pm 1.37$ & 0.245 & $5.08 \pm 1.50$ & -1.667 \\
\hline & & Female & $5.65 \pm 1.47$ & & $5.31 \pm 1.41$ & \\
\hline & Foodservice event & Male & $5.58 \pm 1.45$ & 0.055 & $5.03 \pm 1.41$ & -1.042 \\
\hline & & Female & $5.57 \pm 1.50$ & & $5.17 \pm 1.49$ & \\
\hline & Location of cafeteria & Male & $5.91 \pm 1.30$ & 0.048 & $5.20 \pm 1.65$ & -1.242 \\
\hline & & Female & $5.91 \pm 1.41$ & & $5.38 \pm 1.48$ & \\
\hline & Total & Male & $5.55 \pm 1.45$ & 0.261 & $5.08 \pm 1.51$ & $-2.543 *$ \\
\hline & & Female & $5.50 \pm 1.54$ & & $5.28 \pm 1.47$ & \\
\hline & & Total & $5.52 \pm 1.50$ & & $5.18 \pm 1.49$ & \\
\hline
\end{tabular}


218 ·외국인 유학생의 대학급식 이용실태 및 만족도 조사

Table 6. continued

\begin{tabular}{|c|c|c|c|c|c|c|}
\hline \multicolumn{2}{|c|}{ Factor and variables } & Gender & Importance & t-value & Satisfaction & t-value \\
\hline \multirow[t]{13}{*}{ Service environment } & \multirow[t]{2}{*}{ Comfortable seats } & Male & $5.84 \pm 1.40$ & -1.201 & $5.27 \pm 1.48$ & -1.486 \\
\hline & & Female & $6.00 \pm 1.28$ & & $5.54 \pm 1.37$ & \\
\hline & \multirow[t]{2}{*}{ Functionality as resting place } & Male & $5.85 \pm 1.38$ & -0.091 & $5.25 \pm 1.50$ & -1.959 \\
\hline & & Female & $5.86 \pm 1.35$ & & $5.53 \pm 1.36$ & \\
\hline & \multirow[t]{2}{*}{ Pleasant dining environment } & Male & $6.05 \pm 1.32$ & -1.254 & $5.35 \pm 1.44$ & -2.054 \\
\hline & & Female & $6.20 \pm 1.13$ & & $5.57 \pm 1.40$ & \\
\hline & \multirow{2}{*}{$\begin{array}{l}\text { Presence of drinking water } \\
\quad \text { facilities, serviettes and mirrors }\end{array}$} & Male & $6.16 \pm 1.27$ & -1.486 & $5.60 \pm 1.39$ & -1.630 \\
\hline & & Female & $6.33 \pm 1.05$ & & $5.68 \pm 1.40$ & \\
\hline & \multirow[t]{2}{*}{ Kindness of employee } & Male & $6.13 \pm 1.31$ & $-2.792 * *$ & $5.53 \pm 1.42$ & -1.077 \\
\hline & & Female & $6.45 \pm 0.93$ & & $5.67 \pm 1.32$ & \\
\hline & \multirow[t]{3}{*}{ Total } & Male & $6.01 \pm 1.34$ & -1.275 & $5.40 \pm 1.45$ & $-2.562 *$ \\
\hline & & Female & $6.17 \pm 1.15$ & & $5.60 \pm 1.37$ & \\
\hline & & Total & $6.09 \pm 1.24$ & & $5.50 \pm 1.41$ & \\
\hline \multirow{3}{*}{\multicolumn{2}{|c|}{ Total }} & Male & $5.87 \pm 1.39$ & $-3.111 * *$ & $5.16 \pm 1.52$ & -1.106 \\
\hline & & Female & $6.13 \pm 1.16$ & & $5.26 \pm 1.45$ & \\
\hline & & Total & $6.00 \pm 1.28$ & & $5.21 \pm 1.48$ & \\
\hline
\end{tabular}

1) Mean \pm SD. The importance scores were based on the mean scores measured on a Likert-type scale from 1 to 7 (1: not at all important 4: neither $\sim$ 7: very important).

2) Mean \pm SD. The satisfaction scores were based on the mean scores measured on a Likert-type scale from 1 to 7 (1: not at all satisfied $\sim$ : neither $\sim 7$ : very satisfied).

$*: \mathrm{p}<0.05, * *: \mathrm{p}<0.01, * * * \mathrm{p}<0.001$

도 점수는 성별 차이가 없었다. 각 요인별로 보면, ‘음식의 품 질과 가격' 요인의 중요도 점수 역시 여학생 $(6.14 \pm 1.29)$ 이 남학생 $(5.76 \pm 1.45)$ 보다 높았고 $(\mathrm{p}<0.05), 8$ 개 속성 중 ‘적정 1 인 분량'을 제외한 7 개 속성에서 여학생이 남학생보 다 중요도 점수가 유의하게 높았다. 그러나 만족도 점수는

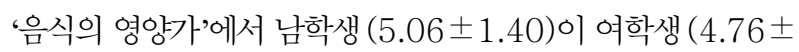
1.59 )보다 유의하게 높았고 $(\mathrm{p}<0.05)$, 다른 7 개 속성들은 모두 남녀 간에 차이가 없었다. 급식의 ‘위생' 요인의 9가지 속성에 대한 중요도 점수는 모두 여학생이 남학생보다 유의 하게 높았다. 만족도 점수는 '식당의 환기'와 '종사원의 위 생' 속성에 대해서는 여학생이 남학생보다 유의적으로 높았 고 $(\mathrm{p}<0.05)$, 다른 속성들에서는 성별에 따른 차이가 없었 다. 급식의 '편의성' 요인의 5 가지 속성에 대한 중요도 점수 역시 모두 여학생이 남학생보다 유의하게 높았다. 이 요인의

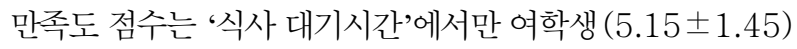
이 남학생 $(4.82 \pm 1.54)$ 보다 유의하게 높았고 $(\mathrm{p}<0.05)$, 다 른 속성들에서는 남녀 간에 차이가 없었다. '물리적 환경' 요 인의 5 가지 속성에 대해서는 중요도와 만족도 점수 모두 성 별에 따른 차이가 없었고, 이 요인의 만족도 평균점수가 여 학생 $(5.28 \pm 1.47)$ 이 남학생 $(5.08 \pm 1.51)$ 에 비해 다소 높 았다 $(\mathrm{p}<0.05)$. 급식의 '서비스 환경' 요인의 5 가지 속성 중

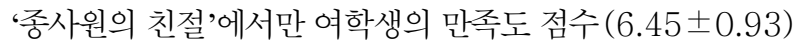
가 남학생 $(6.13 \pm 1.31)$ 보다 유의하게 높았고 $(\mathrm{p}<0.01)$, 다
른 속성들에서는 만족도와 중요도 점수에 성별에 따른 차이 가 없었다. 이 요인의 만족도 평균점수 역시 여학생 (5.60土 $1.37)$ 이 남학생 $(5.40 \pm 1.45)$ 에 비해 높았다 $(\mathrm{p}<0.05)$

\section{고 찰}

본 연구는 부산 소재 대학에 재학 중인 외국인 유학생의 대 학급식 이용실태 및 개선 요구 사항과 대학급식 품질속성에 관한 중요도와 만족도 조사를 실시함으로써 유학생 증가시 대에 발맞추어 이들의 급식만족도를 향상시킬 방안을 마련 하고자 실시되었다.

본 연구에서 전체적으로 대학급식의 식생활 기여도가 낮 게 나타났는데 (Table 2), 이것은 대전지역 중국유학생의 대 부분이 급식에 의존하고 있고 [8], 목포대 중국유학생이 기숙 사 급식을 하루에 2회 이상 이용하는 비율이 $86.8 \%$ 로 대부 분의 식사가 급식으로 이루어지고 있는 것과 비교하면 [7] 매 우 다른 결과이다. 그런데 이들 연구에서 유학생들의 교내 급 식 이용률이 높은 것은 ‘의무식 규정' 때문인 것으로 조사되 어 $[7,8]$ 급식의 의무 규정 존재 여부가 대학급식 이용에 많 은 영향을 미치는 것으로 보인다. 또한 서울, 부산, 대구, 강 원, 충북, 전북 지역의 중국유학생의 경우 기숙사식당을 이 용하는 비율이 $22.6 \%$ 에 불과하였고, 교내 급식은 맛이 없어 서 이용하지 않는다는 비율이 높았다고 보고되어 [13], 유학 
생의 거주지역과 대상자에 따라 연구 결과가 다른 것으로 보 인다.

대학급식을 이용하지 않는 경우, 가장 큰 이유는 '식단이 다양하지 않아서' (32.3\%)였고 그 외에 '위치 또는 이용방 법을 몰라서' $(14.4 \%)$, '맛이 없어서' (9.6\%), '식당 냄새 등 한국 음식 냄새가 싫어서' $(7.8 \%)$, '가격이 비싸서' $(5.8 \%)$, '메뉴에 대한 설명이 없어서'(4.0\%), 종교적 이유 등으로 '먹을 수 있는 메뉴가 없어서' (3.8\%) 등 이었다(Table 2). 다른 연구에서도, 재한 중국유학생이 교내 급식을 이용하지 않는 것은 ‘제한적 메뉴' 및 ‘메뉴의 다양성 부족'과 '맛이 없 어서'가 주된 이유였고 $[7,8]$, 중국유학생의 식생활 관련 스 트레스 중 '학교식당 메뉴의 다양성 부족'이 가장 높은 것으 로 보고되어 [22] 본 연구와 유사한 결과를 보였다. 중국 및 일본유학생의 경우, 급식의 의무 규정 외에 시간 절약, 편리 한 위치, 가까운 거리, 저렴한 가격 등 편리성이 급식을 선택 하는 주된 속성인 것으로 보고되었는데 $[7,8,11]$, 본 연구 결과 급식의 불이용 이유로 나타난 정보 및 설명 부족, 냄새, 가격 등 급식의 편리성에 대해서도 비중 있게 고려해야 할 필 요가 있다고 생각된다.

본 조사에서 유학생이 교내 급식에서 많이 남기는 음식은 김치 (30.3\%), 국 · 탕 · 찌개 (19.2\%), 밥 (11.8\%) 순이었 다(Table 3). 중국유학생 대상 선행 연구에서 교내 급식에 서 가장 많이 남기는 음식은 김치 $(27.5 \%)$, 국 - 탕 - 찌개 (26.3\%)였고 [7], 대전지역 중국 및 일본 유학생 대상 연구 에서도 교내 급식 이용 시 국 · 탕 - 찌개 $(32.0 \%)$, 김치 (27.0\%), 밥 (19.0\%)을 주로 남긴다고 하여 [11], 본 연구 와 유사한 결과를 보였다. 전보에서 보고한 바와 같이 [6] 유 학생들은 김치를 비롯하여 마늘, 고추 등의 강한 양념, 발효 된 장류 등 한국음식에 대한 식생활 적응도가 낮았는데, 급 식 잔반에서도 이러한 한국음식에 대한 부적응 양상이 나타 난 것으로 보인다. 교내 급식에서 음식을 남기는 이유는 입 맛에 맞지 않아서'(27.8\%), ‘양이 너무 많아서'(18.4\%), '향이나 냄새가 싫어서' $(16.3 \%)$, '먹어본 적이 없어서' (13.0\%), ‘싫어하는 음식이거나 식품이어서' $(11.9 \%)$ 순이 었다. Ryu 등의 연구에서도 [11] 재한 중국 및 일본 유학생 의 교내 급식 잔반 이유는 '입맛에 맞지 않아서' $(41.0 \%)$ 가 가장 많았고, '싫어하는 음식이거나 식재료이어서' (26.0\%), ‘양이 너무 많아서' (17.0\%) 순으로 본 연구 결과와 유사하 였다. 본 연구에서, 조사대상자의 교내 급식 개선을 위한 요 구 사항으로는 '메뉴의 다양화' $(52.0 \%)$, ‘음식의 맛 개선' (14.9\%), '급식비 인하' $(11.1 \%)$, ' 1 인 분량 증가' (9.9\%) 등이 있었다. 중국 및 일본유학생을 대상으로 한 다른 연구 에서도 $[11,24]$ 대학급식의 개선사항은 메뉴의 다양화, 맛
개선, 급식비 인하 요구가 가장 많아 본 연구결과와 유사하 였다. 이에 유학생의 대학급식 이용률을 증가시키기 위해서 는 기호 및 선호도를 반영한 다양한 메뉴 개발이 우선적으로 필요하며, 유학생의 잔반 감소를 위하여 김치, 장류, 마늘 등 의 한국음식에 대한 적응도를 높이는 노력과 동시에, 메뉴 계 획 시 유학생의 선호도가 높은 식재료를 반영하고 특유의 강 한 향이나 냄새를 가급적 줄이면서 유학생들에게 특화된 조 리법을 연구하고 개발하는 것이 필요할 것으로 보인다. 또한 적절하지 못한 배식양이 잔반 감량을 위해 개선해야 할 사항 으로 지적되어 적절한 양으로 음식을 담는 배식 방법도 고려 되어야 할 것이다.

본 연구에서, 조사대상자가 가장 선호한 조리법은 육류와 생선류는 구이, 채소류는 생채 · 샐러드였다 (Table 5). Ryu 등의 연구에서 [11] 재한 중국 및 일본 유학생이 선호하는 육 류 조리법은 볶음 (31.6\%)과 구이 (25.9\%)로서, 본 연구 결 과와 유사하게 건열 조리를 선호하는 것으로 나타났다. 그런 데 생선류 조리법은 조림 (26.2\%), 끓이기 (22.4\%), 구이 (21.1\%) 순으로 선호하였고 채소류는 숙채를 선호하였다 고 보고하여 본 연구결과와 다른 양상을 보였다. 또 다른 아 시아권 유학생 대상 연구에서도 선호 조리법이 육류는 찜 (29.3\%), 어패류는 튀김 (41.0\%), 채소류는 샐러드 (32.1\%) 로 조사되어 [23] 역시 본 연구결과와 차이가 있었다. 이러 한 차이는 본 연구 대상자가 선행 연구들과는 달리 이슬람권 등 다양한 국적과 종교를 가지고 있기 때문에 식재료와 조리 법의 선호도 역시 다양하게 나타나는 것으로 생각된다.

조사대상자의 급식 품질속성에 대한 중요도와 만족도를 분 석한 결과 전반적으로 중요도에 비해 만족도가 낮았다 (Fig. 1, Table 6). 재한 중국과 일본 유학생을 대상으로 한 선행 연구에서도 $[7,11]$ 본 연구결과와 마찬가지로 만족도 평가 점수가 중요도에 비해 낮은 것으로 나타났다. 우리나라 대학 생을 대상으로 한 연구들에서 중요도 점수는 5점 만점에 4.18 점 [8]과 3.89점으로 [20] 보고되었는데, 본 연구의 중요도 점수를 5 점 척도로 환산하면 4.29점으로서 우리나라 대학 생의 평가보다 다소 높았다. 반면, 본 결과의 급식 만족도 점 수 $(3.72 / 5$ 점)는 우리나라 남자대학생의 4.62점, 여학생의 4.29점에 비교하여 낮은 수준으로 [19], 따라서 본 연구의 유학생들은 한국대학생에 비해 대학급식 품질속성에 대해 중 요도는 높게 생각하는 한편, 만족도는 낮음을 볼 수 있다.

조사대상자가 급식 품질속성 중 중요하게 생각하는 요인 은 ‘위생'(6.42점), '서비스 환경’(6.09점), ‘편의성' (6.03 점), ‘음식의 품질과 가격'(5.95점), ‘물리적 환경'(5.52점) 순이었다. 만족도는 ‘위생'(5.56점), '서비스 환경'(5.50점), ‘물리적 환경’(5.18점), ‘음식의 품질과 가격' (4.94점), ‘편 
의성 (4.88점) 순이었다. 대학급식에서 우선적으로 심층 관 리가 필요한 부분 (I)은 ‘편의성' 요인으로 분석되었고, 중요 도와 만족도 점수가 함께 높아 앞으로 현재수준을 잘 유지해 야 할 부분 (II)은 ‘위생’과 ‘서비스 환경' 요인이었다(Fig. 1). 중국유학생의 대학 급식 품질 속성을 분석한 선행 연구 에서 $\mathrm{Yi}$ 는 [8] 음식, 서비스, 위생, 편의성 순으로 요인에 대 한 인식이 높을수록 고객만족이 높아진다고 하였고, Jing은 [16] 전반적인 시설과 장비, 편의시설 등이 고객 만족도에 가장 큰 영향을 미친다고 하였다. 대전지역 중국 및 일본유 학생의 급식만족도 연구에서는 위생 및 종사원 서비스 요인 의 만족도가 가장 높았고, 그 다음으로 물리적 환경, 음식의 순으로 본 연구와 유사한 결과를 보였다[11]. 그러나 중국 유학생의 급식 만족도를 평가한 Jung \& Jeon의 연구에서 는 [7] 위생 요인보다는 시설 요인에 대한 만족도가 높아 본 연구의 만족도 순위와 다소 차이를 보였다. 한국 대학생 대 상 연구에서는 본 연구결과와 유사하게 급식 품질속성 중 위 생에 대한 중요성을 가장 높게 인식하고 있었다 $[8,20]$. 그 러나 한국 대학생들에서 만족도가 가장 높았던 급식의 편의 성, 요인이 $[8,20]$ 본 연구에서는 가장 낮은 만족도 수준을 보여 심층관리가 필요한 요인으로 평가되었음을 볼 때, 자국 학생들이 인식하지 못하는 유학생들만의 급식 이용 불편 사 항들이 있을 것으로 생각된다. 이에 앞으로 이들의 급식 이 용 편의성을 향상시킬 수 있는 방안에 대한 연구가 필요한 것 으로 보인다.

본 연구에서 ‘음식의 품질과 가격' 요인 중 중요도는 높은 데 비해 상대적으로 만족도가 낮아 앞으로 집중해서 개선해 야 할 요인은 음식의 맛, 신선도, 영양가, 적정가격 이었다. 급식의 '편의성' 요인 중에서는 다양한 메뉴, 원활한 배식, 식 단 내용 게시 속성이 중요도에 비해 만족도가 낮아 앞으로 이 부분에 대한 우선적 개선이 필요한 것으로 나타났다. '물리 적 환경' 요인은 중요도와 만족도가 다른 요인에 비해 낮은 편이어서 급식품질에 미치는 영향이 비교적 작았고, ‘서비스 환경' 요인 중에서는 ‘쾌적한 식사 환경’과 ‘식사 후 냅킨 · 거울 · 급수시설의 구비', ‘종사원의 친절'이 중요도와 만족 도 점수가 모두 높아 현재 수준을 잘 유지해야 할 속성으로 나타났다. 재한 중국유학생 대상 다른 연구에서, 중요도 평 가점수가 Fan \& Bae는 [17] ‘음식의 위생', ‘음식의 신선 도', ‘음식의 맛', ‘식당의 청결', ‘종사원의 위생', ‘화장실의 청결', ‘음식의 영양', ‘종사원의 친절도' 순으로 높았다고 하 였고, Jung \& Jeon은 [7] ‘식기의 위생', ‘음식의 맛’, ‘음식 의 간’, ‘주방 내부 식당 홀 바닥의 청결', ‘음식의 영양’ 순으 로 높다고 하여 본 연구 결과와 유사하였다. 경북지역 중국 유학생의 급식 만족도 조사 결과[17], ‘음식의 신선도', ‘음
식의 맛’, ‘음식의 온도', ‘적정 가격' 등의 속성이 높게 평가 받아 본 연구결과와 차이가 있었으나, '다양한 메뉴'에 대한 만족도가 가장 낮았던 것은 본 연구 결과와 유사하였다. 또 한 대전지역 중국 및 일본유학생 대상 연구에서 [11] 외국인 유학생을 위한 특별식 제공에 대한 만족도가 가장 낮았는데, 다양하지 않은 메뉴와 제대로 본토 맛을 내지 못하는 유학생 을 위한 특별 메뉴는 유학생 급식만족도에 기여하지 못함을 알 수 있다. 목포대 중국유학생에서도 음식의 맛, 음식의 영 양가, 메뉴의 다양성 등이 중요도는 높으나 만족도가 낮아 개 선되어야 할 속성으로 분석되어 [7] 본 연구 결과와 같은 경 향이었다. 이러한 결과로 볼 때, 앞서 언급된 바와 같이 유학 생들의 요구와 필요를 반영하여 그들의 기호에 맞는 유학생 들에게 특화된 다양한 급식 신메뉴를 개발하는 것이 우선적 으로 필요하리라 생각된다. 외국 대학의 경우 학생 구성원의 변화에 맞추어 아시아식, 이슬람교도식 등 다양한 식문화를 반영한 급식 메뉴를 제공하고 있으며 [23], 최근 국내 급식 업체에서도 외국인 유학생을 비롯하여 한국에서 장기간 체 류하는 외국인들에게 각국의 맞춤형 현지식을 제공하여 급 식 만족도를 높이는 노력을 하고 있다[11]. 본 연구 결과, 유 학생들에게 교내 급식의 식생활 기여도는 낮은 수준이고, 전 보에 보고되었듯이 [6] 유학생들이 교내식당 이용률도 매우 낮은 것을 고려할 때, 급식 품질에 대한 유학생들의 불만이 발생하지 않도록 이들의 요구를 급식 운영에 적극 반영하여 개선할 필요가 있다. 경북지역 중국유학생 대상 연구에서, 현 재 수준을 잘 유지해야 할 급식 속성 항목에 음식의 위생, 식 당의 청결, 화장실의 청결, 종사원의 위생, 종사원 친절 등이 포함되어 [17] 본 연구결과와 유사한 경향을 보였다. 한국 대 학생은 대학급식 품질속성에서 우선적으로 중점 개선해야 할 속성은 음식의 맛, 메뉴 선택의 다양성, 음식의 신선도 등으 로 분석되어 $[7,15,25]$ 자국 대학생들에서도 급식 품질의 기본 요소인 음식 자체의 품질에 대한 개선이 우선적으로 요 구되는 것으로 나타났다. 한편 본 연구에서, 유학생들은 이 러한 음식에 대한 요소 외에도 ‘원활한 배식', '식단 내용 게 시, 등 자국 학생들은 인식하지 못하는 속성을 개선해야 할 속성으로 평가하고 있었다. 따라서 유학생이 보다 용이하게 대학급식을 이용할 수 있도록 교내 식당의 이용 매뉴얼을 제 공하고, 급식 종사자가 유학생들에게 급식 제공 메뉴에 대해 충분히 설명할 수 있도록 교육하는 등의 노력이 필요할 것으 로 생각된다. 유학생의 경우 교내급식에 대한 품질 만족도가 높을수록 학교에 대한 만족도도 높아지기 때문에 [16] 유학 생 유치와 한국에서와 적응을 돕기 위해 급식 만족도 향상을 위한 지원이 필요하리라 생각된다. 


\section{요약 및 결론}

본 연구는 재한 외국인 유학생들을 대상으로 대학급식 이 용 현황 및 개선 요구사항, 선호하는 급식 식재료별 식품 및 조리법, 대학급식 품질속성에 대한 중요도와 만족도를 조사 하여 유학생이 인식하는 대학급식의 문제와 요구를 파악하 고자 하였다. 연구 결과를 요약하면 다음과 같다.

1. 조사대상자에게 교내 급식이 식생활에 기여하는 정도는 ‘적다' 또는 ‘매우 적다’인 비율이 $36.4 \%$ 로 교내 급식의 식 생활 기여도가 낮은 것으로 나타났다. 교내 급식을 이용하지 않는 가장 큰 이유는 '식단이 다양하지 않아서' (32.3\%)였 고, 교내 급식에 요구하는 개선사항 역시 '메뉴의 다양화' (52.0\%)가 가장 많았다.

2. 조사대상자가 대학급식에서 많이 남기는 음식은 김치 (30.3\%), 국 · 탕 · 찌개 (19.2\%) 였고, 잔반을 남기는 이유 는 '입맛에 맞지 않아서' $(27.8 \%)$, '향이나 냄새가 싫어서' (16.3\%) 등으로, 발효음식과 향이 강한 한국음식에 대한 부 적응 양상이 급식 잔반에 나타났다.

3. 조사대상자가 급식에서 가장 선호하는 육류는 소고기, 생선류는 오징어, 채소류는 배추와 오이, 브로콜리였고, 선호 도가 낮은 육류는 양고기와 오리고기, 생선류는 삼치, 가자 미, 채소류는 깻잎, 도라지, 우엉으로 나타났다. 육류 조리법 중에서는 구이와 볶음 등 건열조리를 선호하였고, 생선 조리 역시 찜, 조리 등의 습열 조리보다 구이를 선호하였다. 채소 류 조리법으로는 생채 · 샐러드를 가장 선호하였고, 조림 · 절임이 가장 선호도가 낮았다.

4. 조사대상자의 급식 품질속성에 대한 중요도와 만족도 분석 결과, 전반적으로 중요도에 비해 만족도가 낮았다. 급 식 품질속성 중 위생 요인이 중요도와 만족도 모두 평가점수 가 높았고, 편의성은 중요도는 높으나 만족도는 낮게 평가되 어 대학급식에서 우선적으로 심층 관리가 필요한 요인으로 평가되었다.

5. 급식 품질속성 32 개 속성 중 ‘음식의 맛’, ‘음식의 신선 도' ‘음식의 영양가’, ‘적정 가격, ‘다양한 메뉴’ ‘원활한 배 식, '식단 내용 게시' 등이 중요도는 높으나 만족도가 높지 않아 이 부분에 대한 우선적 개선이 필요한 것으로 나타났 다. 급식의 위생 요인 속성은 모두 중요도와 만족도 점수에 큰 차이 없이 높게 나타나 모든 속성이 현재 수준을 그대로 유지해야 할 것으로 나타났다.

이상의 결과, 교내 급식이 유학생들에게 기여하는 정도는 낮았고 이들의 급식 만족도를 높이기 위해서는 무엇보다 다 양한 메뉴 개발이 필요한 것으로 나타났다. 이를 위해 유학
생을 대상으로 식재료별로 선호도가 높게 나타난 식품 및 조 리법을 반영하고 특유의 강한 향이나 냄새를 가급적 줄이면 서 유학생들의 기호에 맞는 메뉴를 연구하고 개발하는 노력 이 선행되어야 하겠다. 더불어 유학생들이 보다 용이하게 급 식소를 이용할 수 있도록 각 언어권 별로 유학생 대상 교내 급식 이용 안내서를 제작하고 급식 제공 메뉴에 대한 충분한 설명을 제공하는 등 대학급식에 대한 정보 제공을 강화하여 급식의 이용 편의성을 향상시키는 노력도 필요하리라 생각 된다. 본 연구에서는 인구통계학적 다양한 변수를 고려하지 못하였고, 부산 지역 유학생만을 대상으로 실시하였기에 한 계점이 있다. 향후 연구에서는 조사대상자의 국적 및 종교, 한국에서의 체류 기간 등의 변수를 고려하여 분석 - 평가한 다면 유학생들을 위한 대학급식 운영에 보다 많은 시사점을 제시할 수 있을 것이라 판단된다.

\section{ORCID}

Kyung Hee Hong: https://orcid.org/0000-0003-4956-8177

Hyun Sook Lee: https://orcid.org/0000-0002-8642-1978

\section{References}

1. Korean Ministry of Education. Current status of international students at higher education institutions in 2017 [Internet]. 2017 [cited 2017 Sep 29]. Available from: http://www.moe.go.kr.

2. Gaowei, Kim SY, Chang NS, Kim KN. Dietary behavior and nutritional status among Chinese female college students residing in Korea. Korean J Nutr 2013; 46(2): 177-185.

3. Lee HJ, Lee YE, Park EH. Foodservice operational system and satisfaction of customers with foodservice at youth facilities. J Korean Food Sci Nutr 2015; 44(9): 1374-1387.

4. McCool AC, Smith FA, Tucker DL. Dimensions non-commercial foodservice management. 1st ed. NY, USA: Van Nostrand Reinhold; 1994. p. 39-44.

5. Gramling L, Byrd R, Epps L, Keith D, Lick R, Tian R. Foodservice management and its impact college operations: a business anthropological case study. Foodserv Res Int 2005; 16(1): $15-43$.

6. Hong KH, Lee HS. Study of the dietary behaviors and adaptation for Korean foods among international students in Busan. J Korean Soc Food Cult 2018; 33(2): 112-124.

7. Jung HY, Jeon ER. Preference for Korean food and satisfaction of dormitory foodservice by Chinese students studying at Mokpo national university. J Korean Soc Food Sci Nutr 2011; 40(2): 283-289.

8. Yi NY. Mediating effects of perceived value on the relationship between university foodservice quality attributes and satisfaction of Chinese students in Daejeon. J Korean Soc Food Sci Nutr 2015; 44(11): 1750-1758. 
9. Shin JH. International students recruitment and management in Gyeonggi: focus on Chinese students. Gyeonggi Research Institute; 2012 Mar. Report No. 2012-04.

10. Choi JH, Zhang Y, Zheng H, Zhu X. Affecting factors on the living satisfaction degree in university dormitory's service: focusing on the foreign students of "G" university. J Serv Res Stud 2012; 2(2): 99-113.

11. Ryu SH, Cho YH, Han YR. Adaptation for Korean foods and satisfaction for foodservice by different residence periods of Chinese and Japanese university students in Daejeon. J East Asian Soc Dietary Life 2014; 24(1): 143-155.

12. Lim C. Acculturative stresses and adjustment elements of Chinese students' studying in Korea. Korean J Hum Ecol 2009; 18(1): 93-112.

13. Yu L. Study on adaptability and preference of Korean food for Chinese students [master's thesis]. Woosuk University; 2013.

14. Gao RR, Kim JH. Changes in dietary life and health-related lifestyle by stress level in Chinese international students in Korea. J Korean Diet Assoc 2018; 24(1): 75-91.

15. Lee SJ, Jung HY. Identification of quality attributes of university foodservice and factors required for the improvement of customer satisfaction: a case study using IPA model. J Korean Diet Assoc 2010; 16(3): 208-225.

16. Jing Z. Influence of the service quality of university cafeterias on the satisfaction of Chinese students in South Korea [master's thesis]. Daegu University; 2012.

17. Fan MM, Bae HJ. Analyzing the importance and satisfaction on the university foodservice selection attributes of foreign Chinese students in Gyeongbuk province. Korean J Food Nutr 2014; 27(1): 128-135.

18. Yun NY, Choi HS, Lyu ES. Satisfaction of foodservice in high school boarding students in Busan. J Korean Soc Food Sci Nutr 2015; 44(11): 1733-1740.

19. Choi MK, Choi SH, Lee S. An assessment of customer satisfaction towards university residence hall foodservice and subjective QOL (Quality of Life): focused on the university students in Daegu, Gyeongbuk area. Korean J Community Nutr 2009; 14(1): 114-122.

20. Jung HY. A study on utilization and perceived service quality of the university foodservice. J Korean Soc Food Sci Nutr 2013; 42(4): 633-643.

21. Lee SK. Nutrition management, Cornell dining program. Nutrition and Dietetics; 2015 Mar. p. 48-51.

22. Ren L, Jang JS. A study of dietary life related factor according to the acculturation degree on Chinese students in Korea. Korean J Food Nutr 2017; 30(4): 627-634.

23. Lee M, Urkunchiev A, Park S, Aigozhayeva A. Analysis on the cultural adaptation stress of central Asian students in South Korea. J Educ Cult 2015; 21(5): 283-307.

24. Park SJ, Kim JA, Lee SY. A study on attitude satisfaction of service quality in university foodservices. J East Asian Soc Dietary Life 2004; 14(1): 83-91.

25. Yi NY. Importance-performance analysis (IPA) of service quality attributes of university foodservice: A comparison of male and female students' perceptions in Daejeon. Korean J Hum Ecol 2012; 21(2): 389-405. 